\title{
Cross-Cultural Perspectives on Self-Help Groups: Comparison between Participants and Nonparticipants in Israel and the United States
}

\author{
Benjamin Gidron \\ Spitzer Department of Social Work, Ben-Gurion University of the Negev
}

\author{
Mark A. Chesler \\ Department of Sociology, University of Michigan

\section{Barbara K. Chesney} \\ Department of Sociology, Anthropology and Social Work, University of Toledo
}

\begin{abstract}
An exploratory descriptive international study of self-help groups compares self-help groups of parents of children with cancer (U.S.; $\mathrm{N}=116$ ) and parents of mentally ill persons (Israel; $\mathrm{N}=50$ ). Findings indicate that despite different cultures and focal crises, self-help group participants reported very similar benefits and other commonalities. Differences, likely to be related to the two different national service delivery systems and the two different illness foci, were discerned as well. Comparative international research, while posing methodological problems, offers the potential to greatly expand the understanding of universal vs. culture-specific attributes of self-help groups.
\end{abstract}

Since the 1970 s there has been a tremendous expansion of scholarly and practical literature on self-help and mutual aid (e.g., Gartner \& Reissman, 1984; Katz \& Bender, 1976, 1990; Lieberman \& Borman, 1979; Madera, 1986; Surgeon General's Workshop on Self-help and Public Health, 1987). Although self-help itself is not a new phenomenon (Kropotkin, 1902), the number of people and groups actively involved in these social processes has grown considerably during the past several 
decades. Reports from various countries indicate that the development of the self-help phenomenon is not limited to North America, but has become a worldwide development (Branckaerts \& Richardson, 1988; Hatch \& Kickbusch, 1983; Humble \& Unell, 1989; Pancoast, Parker, \& Froland, 1983; Trojan, 1989; Weber \& Cohen, 1982).

Despite the fact that self-help has become an international phenomenon, studies that compare self-help groups in a cross-cultural or international framework are virtually nonexistent. Cross-cultural comparative studies are essential in order to delineate and account for the commonalities and universality of the self-help experience as well as the unique features of self-help in different societies. Groups appear to develop differently in different nations (De Cocq, 1976; Gidron \& Bargal, 1986), and such differential development is rooted in the cultural and politicaleconomic characteristics of different societies, especially in their traditions and resources available for voluntary citizen initiatives. The results of such variation are manifest both in terms of the size of the "self-help sector" in a society and the relative autonomy of its operations.

An exploratory, descriptive, cross-cultural study of self-help groups helping people deal with different stressful life situations was conducted in the United States and Israel in 1987-1989 (Chesler, Chesney, Gidron, Hartman, \& Sunderland, 1988). The study focused on self-help groups of parents of children with cancer (U.S.), parents of murdered children (U.S.), parents of persons with mental illness (Israel), and families of new immigrants (Israel). Informants in this study included people actively participating in these groups, as well as persons experiencing the respective life crisis situation who had not elected to join a group. We report the results of a comparison between participants and nonparticipants in two of these kinds of groups: those for parents of children with cancer (U.S.) and those for parents of persons with mental illness (Israel).

\section{MENTAL ILLNESS, CANCER, AND SELF-HELP GROUPS}

A number of studies have demonstrated that self-help groups of parents of persons with mental illness can provide effective emotional support to their members (Hatfield, 1981; Hatfield \& Lefley, 1987; Medvene \& Krauss, 1989). They also provide members with the opportunity to discuss their problems freely and openly, thus serving as sources of important medical and psychosocial information. Finally, they provide members, some of whom have suffered loneliness and isolation from peer networks, new opportunities for social contacts and an active, empowering public role (Battaglino, 1987; Gidron, Guterman, \& Hartman, 1990). 
In somewhat similar fashion, a number of studies indicate that parents of children with cancer gain from their participation in self-help groups (Belle-Isle \& Conradt, 1979; Knapp \& Hansen, 1973; Monaco, 1988). Most particularly, Chesler and colleagues (Chesler \& Chesney, 1988; Chesler, Barbarin, \& Lebo-Stein, 1985; Chesler \& Yoak, 1984) have shown that these self-help groups sponsor activities aimed at the intellectual, instrumental interpersonal, emotional, and existential stresses common to childhood cancer. By aiding parents in their efforts to cope with these stresses, and by promoting active public stances toward the care-giving system, groups can help (re)empower parents to take control of their lives (Chesler \& Chesney, 1988).

When comparing self-help groups for parents of children with cancer and for parents of persons with mental illness, one must attend to both the similarities and the differences in the nature of the illness and treatment, the populations affected, and the issues they face in maintaining or gaining psychosocial support. For instance, the differences in the ages of children at the onset of the illness (cancer younger) suggest a parallel difference in the ages of their parents. The clarity of a physical (although unknown) cause for childhood cancer, contrasted with public confusion about the cause of mental illness, leads to different forms of social stigma for the family. The duration of the illness (2-5 years in most childhood cancers, a lifetime for mental illness) suggests the need for different coping methods and different systems of social support. We could expect, then, that self-help groups formed for these families might also differ in their activities, goals, foci, and membership patterns.

\section{SOCIETAL STRUCTURES/CULTURES AND SOCIAL SERVICE SYSTEMS}

All types of social support, including self-help, can be expected to reflect the dominant values present in a given culture and to be responsive to the structure and extent of professional social service systems. In some ways, events in both Israel and the United States have encouraged the growth of self-help groups. In both nations the state has supported programs that seek a new mix of public and private, statutory and voluntary, services.

However, the course of self-help group development also appears to differ in these two nations. In the United States, limited commitment to public sector activity, and cutbacks and decentralization of professional health services, have created service gaps that voluntary groups have rushed to meet. The American traditions of local community development and 
voluntary mobilization spur the growth of autonomous and indigenously led self-help groups.

Israel is characterized by a social-democratic political tradition and a semisocialist economy, one which provides a greater range of statesupported social services to citizens in need. Thus, the development of voluntary grass-roots self-help groups is more recent, is less rooted in the society's tradition, and therefore is often facilitated by professionals working for the government Ministries of Health or Labor and Social Welfare. This results in less autonomous self-help groups, ones which are also closely tied to the formal professional service delivery system.

These differences in the culture and socioeconomic systems of Israel and the United States create somewhat different orientations toward selfhelp groups, especially on the part of governmental leaders, professional service providers, and potential members. Moreover, the structure and activities of groups in these two nations appear to differ in response to these external societal forces (Chesler et al., 1988). The examination of such differences, in addition to those differences between families' experiences of cancer and mental illness, clearly requires a comparative analysis.

\section{PARTICIPANTS AND NONPARTICIPANTS IN SELF-HELP GROUPS}

Although any parent facing a family crisis can potentially benefit from participation in a self-help group, it is well known that not all do. Indeed, major questions for both research and practice with self-help groups are who participates, why, and how do they benefit? Although many have pondered these questions, there have been few systematic or controlled studies. The sheer unpredictability of chronic illnesses means that before-after studies are impossible. Moreover, problems of access to families with serious and chronic health conditions have made participant/nonparticipant comparisons quite rare.

Studies that have posed these questions, with various self-help parents' groups (focusing on participants only), have found that participants predominantly tend to be female (Bataligno, 1987; Gottlieb, 1982; Hatfield, 1978; Medvene \& Krauss, 1989; Potasznik \& Nelson, 1984; VidekaSherman, 1982). This finding is explained by females' (mothers') greater responsibility for child care in general, by their more common access to and involvement in the care and monitoring of their children's treatment, as well as by their greater willingness to reach out for social support generally. Studies also suggest that participants most often tend to be 
middle-class and well-educated persons (Medvene \& Krauss, 1989; VidekaSherman, 1982).

Although certain demographic characteristics may provide indirect explanations for self-help group participation (see Powell, 1987, pp. 2123 ), other variables need to be examined as well. Even within educational and income strata there are major differences in self-help group participation, and some groups clearly recruit and sustain members across these class lines. Self-help represents a mode of social support that could be partly explained by culture and class, but also by individuals' typical social behaviors, belief systems and life-outlooks, and accustomed social roles.

This paper compares participants and nonparticipants in self-help groups for parents facing two different chronic illnesses of their children (childhood cancer and mental illness), in two different countries (United States and Israel). The comparison focuses on (a) the types of help parents received and the sources of such help; (b) the changes in their lives since their child's illness; and (c) the benefits received from participation in selfhelp groups (participants only).

\section{METHODS}

Research with self-help groups often poses serious problems of access and credibility. The local and informal nature of these groups requires access to be secured on an individual basis, since no single bureaucratic manager can ensure organization-wide or network-wide collaboration. The informal nature of these grass-roots organizations often makes them wary of strangers, and especially of people "outside" the community of fellow sufferers. Although these cautions were articulated clearly to the researchers in both countries, the study did not encounter serious problems on this score. The lead United States researcher was himself a parent of a child with cancer, an organizer of a local group, and an officer of the national networking and clearinghouse agency for families of children with cancer (The Candlelighters Childhood Cancer Foundation). The lead Israeli researcher had founded and continued to consult with a self-help group for parents of persons with mental illness within Enosh, the Israeli Association for Mental Health.

In both countries, nationwide samples were used; in the United States, data were gathered from 116 parents in 8 childhood cancer treatment sites; 65 parents were participants in local self-help groups and 51 were nonparticipants. In Israel, data were gathered from 50 parents in 5 different communities; 32 parents were participants in self-help groups for 
parents of persons with mental illness and 18 were nonparticipants. Because of our prior study and knowledge about the variety and distribution of these local groups (Gidron \& Bargal, 1986; Yoak \& Chesler, 1985), we are fairly confident that the participant population is roughly similar to the national population of participants in these self-help groups. No similar claim is suggested with regard to the population of nonparticipants. Problems of defining the population of nonparticipants, gaining access to them and their refusals to participate in the study, mandate caution in this regard. Such problems are not unknown in studies on self-help, where difficulties in creating "control groups" are well documented (Powell, 1987).

The major research tool was a questionnaire with structured and open-ended questions about various aspects of informants' lives. These items included social background characteristics, access to various types and sources of social support, perceived life-changes over the course of the illness, and benefits derived from the self-help group. Each of these major dimensions included several questionnaire items and indices, all answered on a 3-, 4- or 5-point Likert-type format. The questions were selected from prior studies of families in crisis (Chesler \& Barbarin, 1987; Platt, 1985; Potasznik \& Nelson, 1984) and were adapted, where appropriate, to mental illness or to childhood cancer, and presented either in English or in Hebrew. Additional data were gathered via in-depth interviews with a subsample of informants and field notes based on visits to local groups and perusals of their meeting minutes, published documents, and records (see Chesler et al., 1988).

\section{RESULTS}

\section{Background Characteristics}

The different nature and timing of these two family health crises are reflected in some of the different background characteristics of informants. The median age of parents of persons with mental illness is 61 , whereas the median age of parents of children with cancer is 35 . The median time elapsed since diagnosis is 13 years for parents of persons with mental illness and 4 years for parents of children with cancer. There are no significant differences between self-help group participants and nonparticipants on these variables. Although females predominate in both the United States (90\%) and Israeli (65\%) samples, gender distributions do not distinguish participants and nonparticipants. Educational level is significantly different for participants and nonparticipants in both the United States and Israeli samples. For instance, in the U.S. sample of parents of children with cancer, 
$52 \%$ of the self-help group participants, compared to $27 \%$ of the nonparticipants, are college graduates. In the Israeli sample of parents of persons with mental illness, $66 \%$ of the self-help group participants, compared with $39 \%$ of the nonparticipants, have 9 years or more of formal schooling. The different national cutting points (16 years of education in the U.S. contrasted with 9 years in Israel) were selected because of the differences in average educational levels in the two nations, especially when one takes into consideration the difference in the average ages of the two groups of respondents.

\section{Types and Sources of Social Support}

Table I presents one-way analysis of variance $F$ tests of participant/ nonparticipant differences within each of the two samples (separate tests for the Israeli and the U.S. populations). It indicates that self-help group participants in the Israeli sample reported receiving more of almost every type of social support than did nonparticipants. These differences were statistically significant, however, only for the items related to "comfort/ emotional support," "care of the ill child," and "give you information." The differences between participants and nonparticipants were smaller and less consistent in the U.S. sample. A statistically significant difference occurred when nonparticipants in self-help groups reported receiving more referrals for assistance that did participants. Participants, on the other hand, reported receiving significantly more assistance in talking about their feelings.

The data in Table I with regard to support received from various sources demonstrate similar findings. Israeli participants in self-help groups reported receiving more support from almost every potential source than did nonparticipants. These differences were statistically significant with regard to health care professionals such as social workers and nurses, and with regard to both items indicating self-help processes themselves ("other parents of ill children" and "the self-help group"). U.S. Nonparticipants in self-help groups reported receiving more help from social workers, while participants in these groups reported receiving more assistance from both of the above sources involved in the self-help process. In general, with regard to both types of help received and sources of assistance, the U.S. sample of parents of children with cancer reported receiving more help than did people in the Israeli sample of parents of persons with mental illness. 


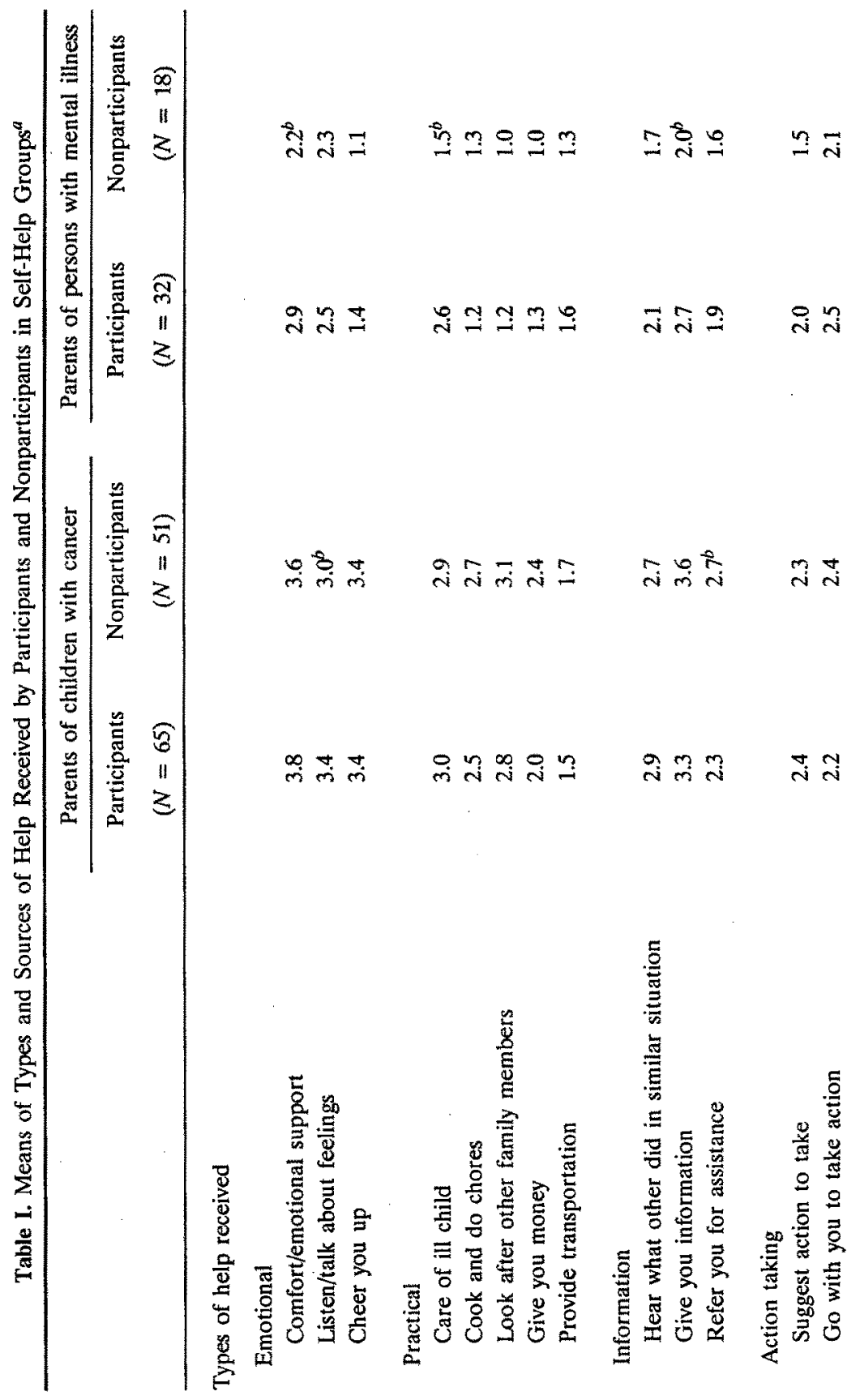




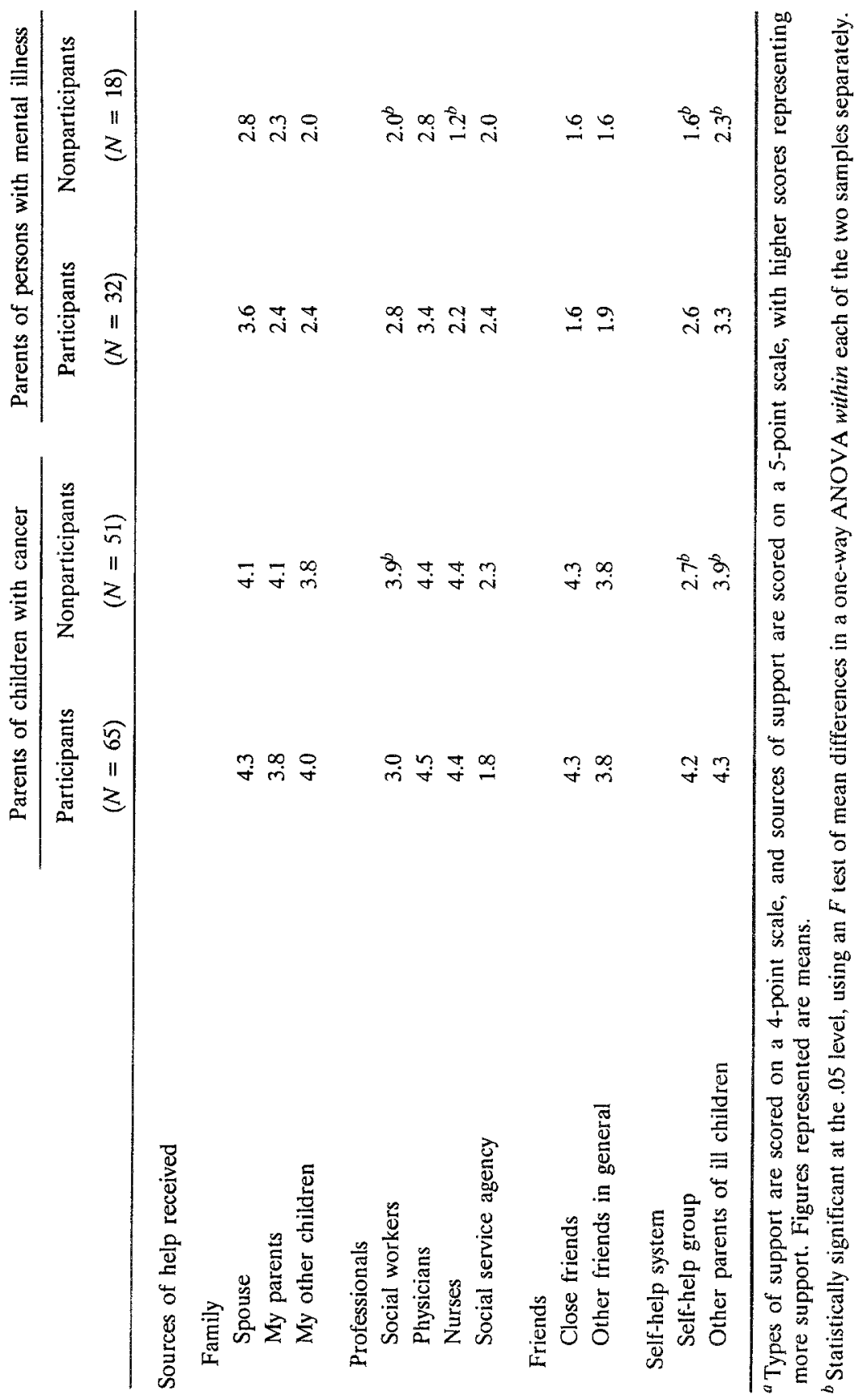




\section{Life Changes}

Table II indicates the extent to which parents in the various samples report that their lives have changed for the better (means between 2.0 and 3.0) or for the worse (means between 2.0 and 1.0) since their child's diagnosis. Parents in the U.S. sample consistently reported more positive changes than did parents in the Israeli sample (whether this is a reflection of the difference in national cultural outlooks or disease-related outlooks is a question we return to later). Differences in reports by U.S. self-help group participants and nonparticipants were evident with regard to items focused upon health, social or public activism, and personal identity; on these items self-help group participants reported significantly more positive life changes that did nonparticipants. The Israeli data regarding participant and nonparticipant differences also demonstrated significantly more positive life changes by participants on the items focused on social or public activism and personal identity.

\section{Self-Help Group Benefits}

Table III presents data reflecting self-help group participants' reports of the benefits they receive from the group (these reports are limited to participants only). Overall, the U.S. parents reported higher levels of benefits from self-help group participation than did the Israeli parents on 11 of the 15 items. The most common benefits reported by Israeli parents are those connected with their sense of identification with a larger collectivity ( $81 \%$ and $77 \%$ report much benefit). Getting information was not an aspect of the Israeli groups from which a high percentage of participants benefited. The most common benefits reported by U.S. parents also include the collective identification items, as well as aid in "coping with my child's problems" and some of the informational items.

A rank-order correlation performed on these two lists of benefits results in a statistically significant (.05 level) Spearman rho $[r(\mathrm{~s})]$ of .63 . This computation suggests a high degree of commonality in the ranking of benefits self-help group members receive in the two samples.

\section{DISCUSSION}

When discussing the results of this study, its exploratory nature must be kept in mind. Our findings therefore should be viewed as indications of certain directions that need confirmation from further studies. Given 


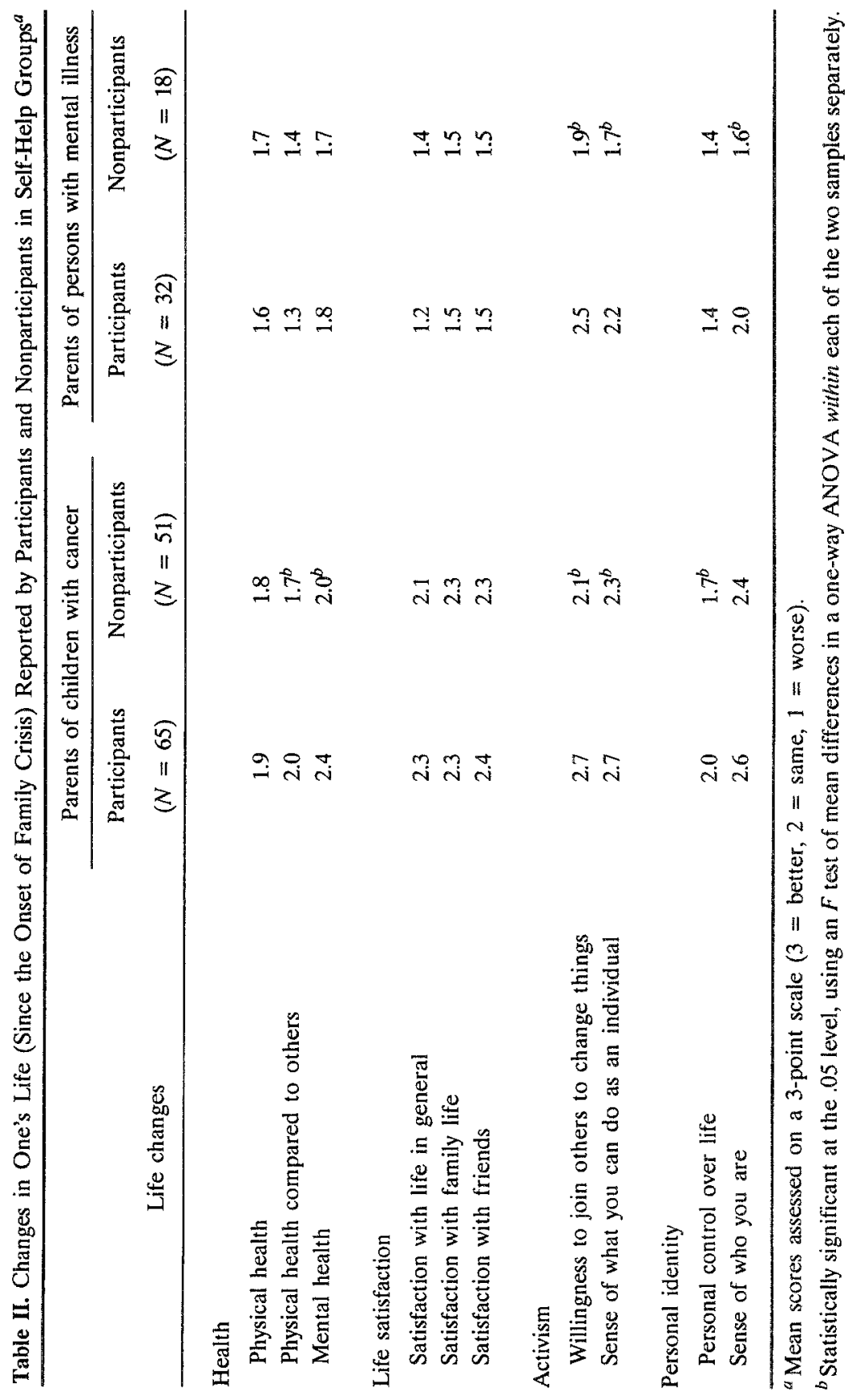


Table III. Benefits from Self-Help Participation (by Participants Only) ${ }^{a}$

\begin{tabular}{|c|c|c|}
\hline Benefits & $\begin{array}{l}\text { Parents of children } \\
\text { with cancer } \\
\text { (U.S.) } \\
(N=65)\end{array}$ & $\begin{array}{c}\text { Parents of mentally } \\
\text { ill persons } \\
\text { (Israel) } \\
(N=32)\end{array}$ \\
\hline Informational & & \\
\hline $\begin{array}{l}\text { Getting information about illness } \\
\text { Learn who's on staff } \\
\text { Learn my rights } \\
\text { Understand treatments }\end{array}$ & $\begin{array}{l}60.0 \\
34.4 \\
43.2 \\
63.1\end{array}$ & $\begin{array}{r}13.6 \\
4.5 \\
9.1 \\
13.6\end{array}$ \\
\hline Practical coping & & \\
\hline $\begin{array}{l}\text { Coping with my child's problems } \\
\text { Coping with problems in my family } \\
\text { Learn to cope differently } \\
\text { Coping with public attitudes }\end{array}$ & $\begin{array}{l}67.7 \\
35.4 \\
35.4 \\
41.5\end{array}$ & $\begin{array}{l}50.0 \\
31.8 \\
30.4 \\
52.2\end{array}$ \\
\hline $\begin{array}{l}\text { Emotional } \\
\text { Freer to express feelings } \\
\text { Get help from other parents }\end{array}$ & $\begin{array}{l}53.8 \\
52.3\end{array}$ & $\begin{array}{l}43.5 \\
47.8\end{array}$ \\
\hline $\begin{array}{l}\text { Social identification } \\
\text { Meet others with similar problems } \\
\text { Feeling part of a larger group }\end{array}$ & $\begin{array}{l}74.6 \\
54.7\end{array}$ & $\begin{array}{l}77.3 \\
81.0\end{array}$ \\
\hline $\begin{array}{l}\text { Activating } \\
\text { Being helpful to others } \\
\text { Develop self-confidence } \\
\text { Active in medical care }\end{array}$ & $\begin{array}{l}56.9 \\
29.7 \\
27.7\end{array}$ & $\begin{array}{r}65.2 \\
8.7 \\
8.7\end{array}$ \\
\hline
\end{tabular}

a Percentage of those answering "much benefit" on 4-point scale from much benefit to not at all. The Spearman rho rank order correlation coefficient, $r(\mathrm{~s})$, for these two rankings is +.63 , which is statistically significant at .05 .

this perspective, and the fact that we compared self-help groups serving people in different life situations and different cultures, it is not surprising that the findings indicate several important differences between the two samples. Yet, on the other hand, the findings also suggest that across cultures and life situations, participants differ from nonparticipants along some similar dimensions; also, that participation in self-help groups appears to lead to a similar sense of benefits and life changes.

Participants in self-help groups for parents of children with cancer (U.S.) and parents of persons with mental illness (Israel) have higher levels 
of education than do nonparticipants. This finding concurs with other studies on the level of education of self-help group participants.

On the measures of social support, we found interesting differences between the Israeli and the U.S. samples. Among the Israeli parents, selfhelp group participants report receiving higher levels of support of almost all types, and from almost all sources, than do nonparticipants. Thus, Israeli parents may experience self-help support as a complement to other sources of support, both from professionals and from informal networks. Among U.S. parents, a different pattern seems to emerge. Nonparticipants report receiving more information and financial assistance than participants, and they receive it from sources where these types of support are readily available: the professionals. Participants in self-help groups, on the other hand, report receiving more emotional support than nonparticipants from a source that readily provides that kind of support: the self-help system. Thus, U.S. parents present a pattern of reliance on the self-help system as a substitute to other sources. This distinction is clearest when parents report the amount of support they receive from social workers. Israeli participants report receiving significantly more help from social workers than do nonparticipants: U.S. participants report receiving significantly less help from social workers than do nonparticipants. This finding also helps explain why nonparticipants in the U.S. groups report receiving more help with finances and with referrals; these resources typically are mediated or delivered by social workers, and the nonparticipants' closer relationship with social workers evidently provides them with greater access to such services. These differences direct our attention towards the differences in the structure of the service delivery systems in both countries and their impact on the roles self-help systems can play within each nation.

Participants in self-help groups in both countries differ significantly from nonparticipants in their sense of social and public activism. This life change outcome has been reported previously as one of the most common products of self-help group participation (Battaglino, 1987; Chesler \& Chesney, 1988; Gidron et al., 1990), and for some scholars and practitioners is the fundamental reason for advocating self-help group activity.

The finding that participants' rankings of the benefits of self-help group involvement are quite similar across life situations and national cultures, is very important, and may suggest the workings of a universal human social process. Interestingly, the actual percentages of informants indicating "much benefit" on most items are very similar. The items on which the two samples differ markedly (information, involvement in medical care) represent areas in which the Israeli self-help groups for parents of persons with mental illness were only minimally engaged or not engaged at all. Thus, the underlying dynamics of self-help appear common in both 
illness situations and in both societies. The personal, social, and perhaps political, importance of meeting others in a similar life situation, of identifying with these others, of sharing feelings and life experiences with them, and of acting together with them, are fundamentally healing and empowering.

The importance of this study also lies in the fact that it is one of the first international comparative studies of self-help groups, identifying certain specific domains for comparison and pointing out important considerations when such research is attempted. The concrete results extend our ability to understand some of the universal principles on which self-help groups function, and some of the common ways in which they provide benefits and improved life outlooks for members. It also points out some of the different ways in which self-help operates in different life circumstances and in different human communities. Needless to say, better insight into these differences would have resulted if we had been able to control the cross-cultural comparison for the focal crisis. Future comparative studies should do so.

\section{REFERENCES}

Battaglino, L. (1987). Family empowerment through self-help groups. In A. Hatfield (Ed.), Families of the mentally ill: Meeting the challenges. San Francisco: Jossey-Bass.

Belle-Isle, J., \& Conradt, B. (1979). Report of a discussion group for parents of children with leukemia. Maternal Child Nursing Journal, 8(1), 49-58.

Brankaerts, J., \& Richardson, A. (1988). Politics and policies on self-help: Notes on the international scene. Health Promotion, 2(3), 275-282.

Chesler, M., \& Barbarin, O. (1987). Childhood cancer and the family. New York: Bruner/Mazel.

Chesler, M., Barbarin, O., \& Lebo-Stein, J. (1984). Patterns of participation in a self-help group for parents of children with cancer. Joumal of Psychosocial Oncology, 2(3/4), 41-64.

Chesler, M., \& Chesney, B. (1988). Self-help groups: Empowerment attitudes and behaviors of disabled or chronically ill persons. In H. Yuker (Ed.), Attitudes towards persons with disabilities. New York: Springer.

Chesler, M., Chesney, B., Gidron, B., Hartman, H., \& Sunderland, S. (1988). Self-help groups: A comparative international study of social support and social action (Final report to U.S.-DHHS, Grant \# 90-PD-0119). Ann Arbor: University of Michigan.

Chesler, M., \& Yoak, M. (1984). Self-help groups for families of children with cancer. In H. Roback (Ed.), Helping patients and their families cope with medical problems. San Francisco: Jossey-Bass.

DeCocq, G. (1976). European and North American self-help movements: Some contrasts. In A. Katz \& E. Bender (Eds.), The strength within us. New York: New Viewpoints.

Gartner, A., \& Riessman, F. (1984). The self-help revolution. New York: Human Sciences.

Gidron, B., \& Bargal, D. (1986). Self-help awareness in Israel: Expressions of structural changes and expanding citizen participation. Journal of Voluntary Action Research, 15(2), 33-46.

Gidron, B., Guterman, N., \& Hartman, H. (1990). Self-help and empowerment. In T. Powell (Ed.), Working with self-help (pp. 267-276). Silver Spring, MD: National Association of Social Workers. 
Gottlieb, B. H. (1982). Mutual-help groups: Members' views of benefits and of roles for professionals. Prevention in Human Services, 1, 55-67.

Hatch, S., \& Kickbusch, I. (Eds.). (1983). Self-help and health in Europe. Copenhagen, Denmark: WHO Regional Office.

Hatfield, A. (1978). Psychological costs of Schizophrenia to the family. Social Work, 23, 355-359.

Hatfield, A. (1981). Self-help groups for the families of the mentally ill. Social Work, 26, 408-413.

Hatfield, A., \& Lefley, H. (Eds.). (1987). Families of the mentally ill. New York: Guilford.

Humble, S., \& Unell, J. (1989). Self-help in health and social welfare: England and Germany. London: Routledge.

Katz, A., \& Bender, E. (Eds.). (1976). The strength within us. New York: New Viewpoints.

Katz, A., \& Bender, E. (Eds.). (1990). Helping one another: Self-help groups in a changing world. Oakland: Third Party.

Knapp, V., \& Hansen, H. (1973). Helping the parents of children with leukemia. Social Work, $18,70-75$.

Kropotkin, P. (1902). Mutual aid. Boston: Porter Sargent.

Lieberman, M. A., \& Borman, L. D. (1979). Self-help groups for coping with crisis: Origins, members, processes, and impact. San Francisco: Jossey-Bass.

Madera, E. (1986). A comprehensive systems approach to promoting mutual aid self-help groups: The New Jersey Self-help Clearinghouse Model. Joumal of Voluntary Action Research, 15(2), 57-63.

Medvene, L. J., and Krauss, D. (1989). Causal attributes and parent-child relationships in a self-help group of families of the mentally ill. Journal of Applied Social Psychology, 19, 1413-30.

Monaco, G. (1988). Parent self-help groups for the families of children with cancer. CA: Journal for Clinicians, 38(3), 169-175.

Pancoast, D., Parker, P., \& Froland, C. (1983). Rediscovering self-help: Its role in social care. Beverly Hills: Sage.

Platt, S. (1985). Measuring the burden of psychiatric illness on the family: An evaluation of some rating scales. Psychiatric Medicine, 15, 383-393.

Potasznik, H., \& Nelson, G. (1984). Stress and social support: The burden experienced by the family of a mentally ill person. American Journal of Community Psychology, 12, 589-607.

Powell, T. (1987). Self-help organizations and professional practice. Silver Spring, MD: National Association of Social Workers.

Surgeon General's Workshop on Self-Help and Public Health. (1987). Los Angeles: UCLA.

Trojan, A. (1989). Benefits of self-help groups: A survey of 232 members form sixty-five disease-related groups. Social Science and Medicine, 29, 225-232.

Videka-Sherman, L. (1982). Effects of participation in a self-help group for bereaved parents: Compassionate friends. in L. D. Borman, L. E. Borck, R. Hess, \& F. L. Pasquale (Eds.), Helping people to help themselves (pp. 69-77). New York: Haworth.

Weber, G., \& Cohen, L. (Eds.). (1982). Beliefs and self-help. New York: Human Sciences.

Yoak, M., \& Chesler, M. (1985). Alternative professional roles in health care delivery: Leadership patterns in self-help groups. Journal of Applied Behavioral Sciences, 21, 427-444. 